\title{
- Delayed Anticipatory Spoken Language Processing in Adults with Dyslexia- Evidence from Eye-tracking
}

\author{
Falk Huettig ${ }^{1 *}$ and Susanne Brouwer ${ }^{2}$ \\ 'Max Planck Institute for Psycholinguistics, Nijmegen, Netherlands \\ ${ }^{2}$ University of Utrecht, Utrecht, Netherlands
}

\begin{abstract}
It is now well established that anticipation of upcoming input is a key characteristic of spoken language comprehension. It has also frequently been observed that literacy influences spoken language processing. Here, we investigated whether anticipatory spoken language processing is related to individuals' word reading abilities. Dutch adults with dyslexia and a control group participated in two eye-tracking experiments. Experiment I was conducted to assess whether adults with dyslexia show the typical language-mediated eye gaze patterns. Eye movements of both adults with and without dyslexia closely replicated earlier research: spoken language is used to direct attention to relevant objects in the environment in a closely time-locked manner. In Experiment 2, participants received instructions (e.g., 'Kijk naar de ${ }_{\mathrm{CO}}$ afgebeelde pianocom', look at the displayed piano) while viewing four objects. Articles (Dutch 'het' or 'de') were gender marked such that the article agreed in gender only with the target, and thus, participants could use gender information from the article to predict the target object. The adults with dyslexia anticipated the target objects but much later than the controls. Moreover, participants' word reading scores correlated positively with their anticipatory eye movements. We conclude by discussing the mechanisms by which reading abilities may influence predictive language processing. Copyright $\odot 2015$ John Wiley \& Sons, Ltd.
\end{abstract}

Keywords: spoken language processing; dyslexia; prediction; visual world paradigm

\section{INTRODUCTION}

One reason why language processing is so effortless, accurate, and efficient is that mature (e.g., Altmann \& Kamide, 1999; DeLong, Urbach, \& Kutas, 2005; Federmeier \& Kutas, 1999; Van Berkum, Brown, Zwitserlood, Kooijman, \& Hagoort, 2005; Wicha, Moreno, \& Kutas, 2004) and developing (e.g., Borovsky, Elman, \& Fernald, 20I2; Mani \& Huettig, 2012; Nation, Marshall, \& Altmann, 2003) language users predict upcoming language input. Eye-tracking studies, for instance, have shown that listeners can use many types of information in the unfolding speech input as cues for prediction including verb semantics (e.g., Altmann \& Kamide, 1999; Mani \& Huettig, 2012; cf. Huettig \& Altmann, 2005), case marking (e.g., Kamide, Scheepers, \& Altmann, 2003), prosody (e.g., Weber,

\footnotetext{
*Correspondence to: Falk Huettig, Max Planck Institute for Psycholinguistics, Wundtlaan I, Nijmegen, 6525 XD, Netherlands. E-mail: falk.huettig@mpi.nl
} 
Grice, \& Crocker, 2006), and visually presented events (e.g., Knoeferle, Crocker, Scheepers, \& Pickering, 2005). In short, prediction appears to be a key characteristic of language processing in line with several recent theoretical accounts (e.g., Altmann \& Mirković, 2009; Dell \& Chang, 20l4; Huettig, in press; Pickering \& Garrod, 2013).

It is noteworthy that most of the aforementioned studies have been conducted with highly literate participants (i.e., undergraduate students). This is an important issue for psychological research in general because it has been proposed that prediction is a fundamental principle of human cognition (Clark, 2013; James, 1890; Pezzulo, Falcone, \& Hoffmann, 2007). In many areas of psychology, however, it has been demonstrated that prediction abilities are fundamentally linked to levels of expertise at the task at hand. Research in sports psychology for example has found that elite basketball players predict the success of free shots at baskets earlier and more accurately than amateurs. Findings like this are typically assumed to be due to the fine-tuning of anticipatory mechanisms that enable athletes to predict other's actions prior to their realization (Aglioti, Cesari, Romani, \& Urgesi, 2008). The question we explore in this paper is whether language expertise, more specifically differing reading abilities as shown in differences in word and pseudoword reading skills between adults with dyslexia and adults without reading impairments, modulate anticipatory spoken language processing. The possibility for such an influence is supported by experimental studies assessing illiterate adults (Huettig \& Mishra, 20I4, for review), developing children as they learn to read, and individuals with dyslexia. Such studies have demonstrated several influences of literacy on spoken language processing to which we now turn.

\section{Effects of Literacy on Spoken Language Processing}

Serniclaes, Ventura, Morais, and Kolinsky (2005) conducted a study investigating categorical perception in Portuguese illiterate participants. Categorical perception is the term given to explain experimental findings that changes in a sound along a continuum are typically perceived not as continuous but as instances of discrete categories. In this task, participants have to judge CV syllables from a continuum of speech sounds (e.g., /da/.../ba/) and are asked to indicate which stimuli they heard. Typically, participants judge stimuli to be consistently either /da/ or /ba/ leading to a steep slope at the category boundary in identification curves (hence categorical perception). Serniclaes et al. (2005) found overall very similar performance of illiterates and literates on $/ \mathrm{ba} /-/ \mathrm{da} /$ contrasts with this task but observed that illiterates had a less precise categorical boundary and a stronger lexical bias. The lexical bias effect refers to observations that lexical information can bias categorization of ambiguous speech sounds. In Portuguese, the syllable /ba/ is a nonword, but the syllable /da/ is a frequent word translating as 'give me'. In other words, illiterates' categorical perception was found to be similar to the literate participants responses but showed more of an influence of the knowledge of existing words. The Serniclaes et al. (2005) study suggests that low level speech perception abilities are largely unaffected by literacy levels.

Tallal (1980) on the other hand has argued that reading impairment in individuals with dyslexia is caused by poor auditory abilities. In line with this suggestion, a number of studies (Godfrey, Sydral-Lasky, Millay, \& Knox, 1981; Hurford \& Sanders, 1990; Mody, Studdert-Kennedy, \& Brady, 1997; Reed, 1989; Tallal, 
1980) have reported worse performance of dyslexic participants in tasks testing low level speech perception such as the categorical perception task. Most of the studies reporting categorical perception in dyslexics have used synthetic speech. This has been criticized (Blomert \& Mitterer, 2004) as a poor choice because there is evidence that performance on synthetic continua only weakly predicts comprehension of natural speech. When a stimulus continuum based on natural speech is used, no perception deficits in dyslexics are observed.

Studies that tap more implicit phonological processing, in contrast to studies using low level speech categorization tasks, have demonstrated clear and consistent differences of literacy on performance. A great number of studies have demonstrated poor performance in phonological awareness tasks in illiterates and individuals with dyslexia. It is uncertain whether tasks that tap explicit phonological knowledge such as phonological awareness tasks are ecologically valid with regard to real-time speech processing (cf. Reis, Guerreiro, \& Petersson, 2003). Phonological awareness appears not to be necessary for speech communication. Moreover, our current study uses a task that measures moment-by-moment spoken language processing (i.e., visual world eye-tracking). We restrict our discussion here therefore to online tasks. Pseudoword (or nonword) repetition is a task that is likely to require both explicit and implicit phonological processing. Reis and Castro-Caldas (1997) found that illiterates performed much worse than literates in repeating pseudowords but as well as literates when they had to repeat real words (see also Kosmidis, Tsapkini, Folia, Vlahou, \& Kiosseoglou, 2004). Petersson, Reis, Askelöf, Castro-Caldas, and Ingvar (2000) speculated that illiterates' difficulty in pseudoword repetition is caused by impaired processing at the level of sublexical phonological structure.

Spoken language processing is transitory and dynamic in nature, and it is important to use experimental techniques that allow the researcher to measure ongoing processing while participants' task activities can continue without being interrupted. Huettig, Singh, and Mishra (20I I) administered an online eye-tracking task (the so-called visual world paradigm; Cooper, 1974; Tanenhaus, SpiveyKnowlton, Eberhard, \& Sedivy, 1995) in which language and vision interact to examine how individuals differing in literacy use phonological and semantic information. In the visual world method, on each trial, participants hear spoken language while looking at a visual display. Participants' eye movements are recorded for later analyses. Note that fixations and saccades are relatively discrete events, and therefore, data from a single trial cannot provide information about the continuous processing of the speech signal (e.g., the gradual activation of word candidates or the gradual deactivation of competing words). By averaging across trials and participants, however, it can be computed how likely listeners are on average at a given moment in time to look at each of the areas of interest. Based on these eye gaze data, inferences about the time course of the underlying cognitive processes can be drawn (see Huettig, Rommers, \& Meyer, 20II, for further discussion and a recent review of the method and Smith et al., 2013, for evidence from a computational model). In the Huettig, Singh, et al. (20I I) study, Indian high and low literate participants listened to simple spoken sentences such as 'Today he saw a crocodile'. While participants listened to these sentences, they looked at a visual scene of four objects. Previous studies (Huettig \& McQueen, 2007; cf. McQueen \& Huettig, 20l4) have shown that participants who are given a few seconds preview of the visual display retrieve phonological (i.e., the object's name) 
and semantic information from the objects in a visual scene and use this information to allocate their overt visual attention (i.e., eye gaze) as the spoken words acoustically unfold. These studies have demonstrated that objects in the visual display that overlap in phonological and semantic information with the information accessed from the spoken word compete for visual attention. Huettig and McQueen (2007) found that in highly literate participants (i.e., university students), looks to phonological competitors in the visual scene (e.g., looks to a crocus, both crocus and crocodile share the same word-initial phonological information) precede looks to semantic competitors (e.g., a turtle, both crocodiles and turtles are semantically related, they are both reptiles). Given the differences in offline phonological tasks between illiterate and literates, Huettig, Singh, et al. (20I I) examined whether low and high literates show differences in phonologically mediated eye gaze behaviour. Indian high literates with 15 mean years and low literates with 2 mean years of formal education listened to the sentences containing a target word (e.g., 'magar', crocodile) while looking at a the visual scene. The visual scene contained a phonological competitor of the target word (e.g., 'matar', peas), a semantic competitor (e.g., 'kachuwa', turtle), and two completely unrelated distractor objects (a rose and a sandal). In a second experiment, the semantic competitors were replaced with another unrelated distractor. In the first experiment, both low and high literates looked at the semantic competitors as the target words acoustically unfolded. In both experiments, high literates looked at the phonological competitors as soon as phonological information became available and moved their eyes away as soon as the acoustic information mismatched. Low literates, however, only used phonological information when semantic matches between spoken word and visual referent were not possible (Experiment 2), and in contrast to high literates, this phonological word-object mapping was not closely time locked to the concurrent speech. Thus, low literates appear not to exploit phonological matches between spoken words and visual referents for language-mediated visual orienting in an efficient manner (see also Smith, Monaghan, \& Huettig, 20I4, for evidence from a computational model that literacy may mediate these effects by changes in the grain size of phonological mappings).

In short, reading acquisition appears to cause considerable changes in phonological processing. These results fit with proposals that link differences in phonological processing between poor and good readers to acquisition of orthographic representations (Frost \& Katz, 1989; Pattamadilok, Perre, Dufau, \& Ziegler, 2009; Seidenberg \& McClelland, 1989; Ziegler \& Ferrand, 1998). Indeed, many studies have demonstrated that orthographic representations influence literate listeners' spoken word processing (Dijkstra, Roelofs, \& Fieuws, 1995; Hallé, Chéreau, \& Segui, 2000; Ziegler \& Ferrand, 1998).

The direction of the relationship between reading acquisition and phonological processing in illiterate adults (whose cause of literacy are socioeconomic factors) seems straightforward. The direction of the relation between reading and phonological processing in individuals with reading impairments is less clear. There appears to be an emerging consensus that a deficit in phonological processing is causally implicated in the reading difficulties of individuals with dyslexia (e.g., Goswami, 2003; but see Hari \& Renvall, 200I; Nicolson, Fawcett, \& Dean, 200I; Stein, Talcott, \& Walsh, 2000, for different views). However, given the results from illiterate adults, it is very likely that reduced reading 
experience in individuals with dyslexia also impacts their phonological processing. Findings such as the poor performance in reading regular words (DiBenedetto, Richardson, \& Kochnower, 1983; Kochnower, Richardson, \& DiBenedetto, 1983) and pseudowords (Baddeley, Ellis, Miles, \& Lewis, 1982; Holligan \& Johnston, 1988; Olson, Kliegl, Davidson, \& Foltz, 1985; Olson, Wise, Conners, \& Rack, 1990; Snowling, 1980, I98I), and in pseudoword repetition tasks of children with dyslexia (Brady, Shankweiler, \& Mann, 1983; Kamhi \& Catts, 1986; Roodenrys \& Stokes, 200I; Snowling, 198I; Snowling, Goulandris, Bowlby, \& Howell, 1986), for example, do not tell us much about the direction of causality. Note in this regard, however, that for the purpose of the present study, we remain agnostic about the possible causes of dyslexia. Our aim here is to investigate the possibility of a relation between the reduced reading abilities of adults with dyslexia and anticipatory spoken language processing.

\section{Effects of Literacy on Language-mediated Anticipatory Eye Movements}

The research described earlier hints at a link between reading ability and spoken language processing. Two previous studies also suggest a link between reading abilities and anticipatory spoken language processing. Mishra, Singh, Pandey, and Huettig (2012) presented Indian low and high literates with simple every day spoken sentences containing a target word (e.g., 'door'). While participants listened to the sentences, they looked at a visual display of four objects (a target, i.e., the door, and three distractors). The spoken sentences were constructed to encourage anticipatory eye movements to the visual target objects. The high literacy group started to shift their eye gaze to the target object well before target word onset. The low literates did not anticipate the targets and looked at the target objects more than a second later, that is, well after the onset of the target. These findings suggest that literacy modulates predictive spoken language processing. High reading proficiency appears to be important even for prediction in basic every day spoken language processing.

Mani and Huettig (2014) explored recently the role of word reading skill in listener's anticipation of upcoming spoken language input in children at the cusp of literacy acquisition. They reasoned that if literacy really does impact predictive language processing, then children at this stage of literacy acquisition should be most susceptible to the effects of literacy on anticipation. Mani and Huettig tested 8-year-old German children on their prediction of upcoming spoken language input in a similar eye-tracking task. While children, like in previous studies to date, were successfully able to anticipate upcoming spoken language input, there was a robust positive correlation between children's word reading (but not their pseudoword reading and meta-phonological awareness or their spoken word recognition) skills and their prediction skills. Mani and Huettig argued that these findings are most compatible with the notion that the process of learning orthographic representations during reading acquisition sharpens pre-existing lexical representations that in turn supports anticipation of upcoming spoken words. In other words, orthographic exposure may provide listeners with additional representations that results in lexical representations becoming sharper and hence in lexical representations becoming available more quickly during online speech processing. 


\section{Dyslexia and Anticipation}

To our knowledge, no studies have explored anticipatory spoken language processing in individuals with dyslexia. Nation et al. (2003) presented skilled and less skilled comprehenders ( 10 or I I years of age) with a visual scene and concurrent spoken sentences such as 'Jane watched her mother choose the cake' (all objects in the scene were choosable) or 'Jane watched her mother eat the cake' (the cake was the only edible object in the display). Less skilled comprehenders were matched to the control children for nonword reading scores but scored below average on a reading comprehension test. Skilled and less skilled comprehenders did not differ in the speed of their language-mediated anticipatory eye movements to the target objects. With regard to more general (non-linguistic) anticipation skills, Stoodley and Stein (2006) found that individuals with dyslexia and poor readers showed a general motor slowing related to a general deficit in processing speed. Wolff (2002) found that during a motor sequencing task, participants with dyslexia ( 10 to I6 years of age) took three or four times as long as normal readers to anticipate the signal of an isochronic pacing metronome. Participants with dyslexia also took significantly longer than normal readers to switch back to anticipation mode after an abrupt change in the metronome rate.

\section{Present Study}

We conducted two eye-tracking experiments and administered four control tasks (assessing word reading, pseudoword reading, pseudoword spelling, and verbal competence) to Dutch adults who had previously been diagnosed with dyslexia and a control group of participants with no history of reading disorders. Given the previously observed differences in phonologically mediated word-object mapping between low and high literates, Experiment I was conducted to assess whether adults with dyslexia showed similar language-mediated eye gaze patterns as high literates. We chose to replicate Experiment I reported in Huettig and McQueen (2007) because it allowed us to assess the word-object mapping of different types of information (i.e., phonological, semantic, and visual shape). Early looks to phonological competitors, for instance, are indicative of phonological word-object mapping (see Huettig, Mishra, \& Olivers, 20I2, for further discussion). Experiment I therefore allowed us to assess whether spoken language-mediated eye gaze, more specifically spoken word-object mapping in adults with dyslexia, is as efficient as in control participants without a history of reading impairments.

The main purpose of our study (Experiment 2), however, was to assess language-mediated anticipatory eye movements in adults with dyslexia. In order to minimize the likelihood that anticipation would be driven by simple word associations (for instance between verb and noun, e.g., eat and cake as in "eat the cake'), we presented participants with simple Dutch spoken instructions such as 'kijk naar de afgebeelde piano' (look at the displayed piano) while they were looking at the target object (e.g., piano) and three unrelated distractor objects. Critically, the Dutch articles 'de' or 'het' were the only cues in the sentence that could be used for anticipation. Dutch has a two-way gender system and makes a distinction between common and neuter gender. Grammatical gender in Dutch is marked on a number of agreeing elements accompanying the noun or referring to it; these include determiners, adjectives, demonstratives, and pronouns (see 
Blom, Polišenská, \& Weerman, 2008). The focus in the present study was restricted to definite determiners. Common nouns are preceded by the definite determiner de, as in de piano 'the piano', whereas neuter nouns are preceded by the definite determiner het, as in het paard 'the horse'. Participants could use gender information from the article for prediction because only the targets but not the unrelated distractors agreed in gender with the article presented in the spoken sentence. Given the previously observed literacy-related differences in anticipatory eye movements between low and high literate adults and in children at the cusp of literacy acquisition, we predicted earlier anticipatory eye movements to target objects for participants with no reading disorders than participants with dyslexia.

\section{EXPERIMENT I}

\section{Participants}

Forty-four Dutch participants were paid to take part in the study. All gave informed consent. Twenty-two of the participants ( 15 women, mean age 21 years, range 18 to 25) had previously been diagnosed with dyslexia. Adults with dyslexia were recruited via advertisements in local newspapers. Participants in the two groups were matched on number of years of education. Two of the participants in this group followed I 8 years of education, I 9 other participants completed I3-I4 years of education, and one participant completed 8 years of education. Twenty-two other participants (20 women, mean age 20 years, range 18 to 26 ) had no history of language disorders. These participants were also recruited via advertisements in local newspapers or were part of the participant panel of the Max Planck Institute for Psycholinguistics in Nijmegen. Two of the participants in this group had completed 18 years of education, 18 others had completed 13-14 years of education, and two had completed 8 years of education. The dyslexia and the control groups did not differ significantly from each other in terms of years of education $(p>.05)$ nor in years of age $(p>.05)$. All participants were native speakers of Dutch, had normal or corrected-to-normal vision, and no hearing problems.

\section{Materials and Design}

In Experiment I, we used exactly the same spoken words and visual materials as Huettig and McQueen (2007, Experiment I, see APPENDIX A). There were 40 experimental trials and 40 filler trials. On each trial, participants heard a critical target word (e.g., 'beker', beaker) and saw a visual display with four spatially distinct objects. On experimental trials (see Figure I as an example), one of the four objects was a shape competitor of the target word (an object similar in shape to the referent of the target word but unrelated in phonology and semantics, e.g., klos, bobbin-bobbins and beakers have a similar global shape). A second object was a semantic competitor (an object similar in semantics to the target word but unrelated in phonology and shape, e.g., vork, fork) of the target. A third object functioned as a phonological competitor. The phonological competitors of the critical word had the same consonantal onset and vowel nucleus as the first (or only) syllable of the name of the critical word (e.g., 'beaver', bever and beker). 


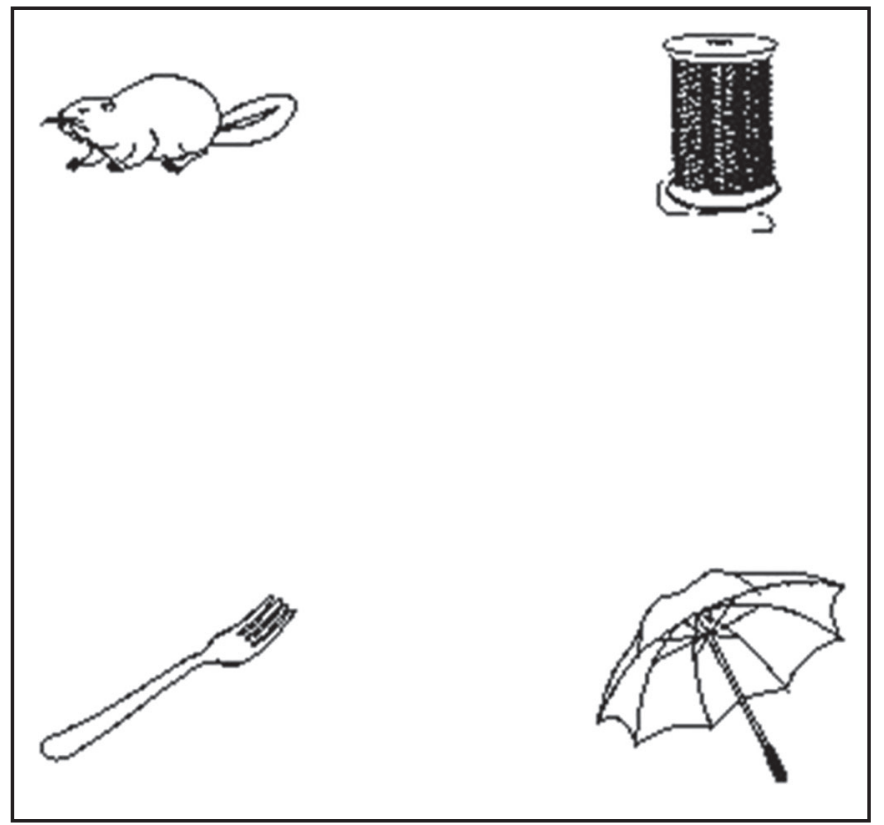

Figure I. Example display for one trial of Experiment I. The spoken target word was 'beker'-beaker. Depicted in the display were a phonological competitor (bever, beaver), a semantic competitor (vork, fork), a shape competitor (klos, bobbin), and an unrelated distractor (paraplu, umbrella).

The fourth object in the display (paraplu, umbrella, the unrelated distractor) was unrelated to the spoken target word on all three dimensions and served as a control. The average target word duration was $437 \mathrm{~ms}$. Filler visual displays included the picture associated with that word (a picture of a cat if the spoken filler word was 'cat') and three completely unrelated pictures (for further details of the materials, including results of rating studies, see Huettig \& McQueen, 2007).

Control tasks

Word reading

Abilities were assessed using the standardized Een Minuut Test (One-Minute-Test; Brus \& Voeten, 1973). The test consists of II 6 words of increasing difficulty. Participants were asked to read out loud and correctly as many words as possible in I min. The score is the amount of accurately read words in I min. A word was scored incorrect if the participant did not produce the exact canonical form of the word as written on the test form.

Pseudoword reading

Abilities were assessed by administering the standardized Klepel test (van den Bos, Spelberg, Scheepstra, \& De Vries, 1994). The Klepel test consists of II6 pseudowords of increasing difficulty. Participants were asked to read out loud and correctly as many words as possible in $2 \mathrm{~min}$. Errors were dealt with in the same way as in the word reading task. 
Spelling

To assess our participants' spelling abilities, we administered the Pseudowoord dictee (a pseudoword spelling) test. The Pl-dictee (Geelhoed \& Reitsma, 1999) is a standardized spelling test consisting of parallel forms (A and $B)$, each containing I 35 words that gradually increase in difficulty. Both monosyllabic and polysyllabic words are included that are commonly known to children of their age. In this task, participants listened to a pseudoword (presented as a digital recording) and were asked to write down what they heard. Words that did not match the exact spelling of the presented words were scored as incorrect.

\section{Verbal competence}

To make sure that any differences in reading abilities between participants were not due to a deficit in more general verbal abilities, we administered a verbal competence task (Analogies) taken from the Dutch version of the Wechsler Adult Intelligence Scale (Wechsler, 2000). Participants were presented with word pairs and were instructed to indicate the analogy between the two words. For example, participants were asked to explain how 'anger' and 'delight' are similar. The tests measures logical thinking and verbal abstract reasoning. It is an untimed test. Errors were based on a mismatch between the response of the participant and the response on the standardized answer sheet.

\section{Control Tasks Results}

Table I shows the results of three screening tasks of the Dutch reading and writing test battery, and the verbal competence task. A statistical analysis of the accuracy pattern was carried out using linear mixed effects models (Baayen, Davidson, \& Bates, 2008) with participants and items as random intercepts. Group was coded as a numeric contrast $(-0.5$ and 0.5$)$ in which the adults with dyslexia were coded as -0.5 and control participants as 0.5 . A logistic linking function was used for the error pattern (cf. Dixon, 2008). Significant differences between the two groups were found on the One-Minute-Test $\left(\beta_{\mathrm{GROUP}}=6.12, p<.00 \mathrm{I}\right)$, the Klepel test $\left(\beta_{\mathrm{GROUP}}=2.64, p<.00 \mathrm{I}\right)$, and the Pseudoword spelling task $\left(\beta_{\mathrm{GROUP}}=0.62\right.$, $p<.00 \mathrm{I})$. As expected, on all these tests, participants in the control group outperformed the adults with dyslexia. Importantly, performance on the verbal competence task of the Wechsler Adult Intelligence Scale showed no group differences $\left(\beta_{\text {GROUP }}=0.26, p>. I\right)$, suggesting that the reading difficulties in the adults with dyslexia were not due to a more general deficit in verbal abilities.

Table I. Average test scores (standard deviation in parentheses) for the two participant groups

\begin{tabular}{lcccc}
\hline & One-Minute-Test & Klepel & Pseudoword spelling & Verbal competence \\
\hline Adults with dyslexia & $70(46)$ & $60(49)$ & $60(49)$ & $65(48)$ \\
Controls & $86(34)$ & $84(36)$ & $70(46)$ & $66(47)$ \\
\hline
\end{tabular}




\section{Procedure}

All participants took part in both eye-tracking experiments and in the four control tasks (administered in the same order: Experiment I then 2, followed by the control tasks). Participants were tested individually and seated at a comfortable distance from the computer screen. Eye movements were recorded with an SR Research Eyelink 1000 Tower mount system sampling at $1000 \mathrm{~Hz}$. The system was calibrated using the standard Eyelink setup. Spoken materials were presented via headphones. The positions of the pictures were randomized. On the beginning of each trial, a central fixation dot appeared allowing for drift correction. Then, the visual displays appeared. Four thousand milliseconds after the pictures appeared, the auditory presentation of the spoken target words was initiated. After the offset of the spoken word, the display remained on the screen for a further $3000 \mathrm{~ms}$, followed by a $500 \mathrm{~ms}$ blank screen. Participants were asked to listen to the spoken words (e.g., 'beaker') carefully and respond by saying 'yes' if the object was present in the display and say 'no' if the object was absent. Participants' responses were recorded. The whole experiment lasted around $20 \mathrm{~min}$.

After participants finished the eye-tracking experiments, the control tasks were administered in the following order: the Een Minuut Test, the Klepel test, the spelling task, and, finally, the verbal competence task. The experimenter was blind to the experimental hypotheses.

\section{Data coding procedure}

Data for both eye-tracking experiments were coded as fixations, saccades, or blinks using the Eyelink algorithm. The timing of the fixations was established relative to the onset of the critical word (target word in Experiment I and article in Experiment 2). Gaze position was categorized by object quadrant. In Experiment I, fixations were coded as directed to the phonological competitor, the semantic competitor, the shape competitor, or the unrelated distractor. In Experiment 2, fixations were coded as directed to the target objects or the unrelated distractors.

\section{Results}

Figure 2 shows a time-course graph of the proportions of fixations to the different types of pictures (phonological competitor, semantic competitor, shape competitor, and unrelated distractor). The proportions reflect the number of trials in which participants were fixating each type of picture on the screen. Time zero represents the acoustic onset of the spoken word.

The graph reveals that both groups' fixation patterns very closely match the ones observed in Huettig and McQueen (2007, Experiment I). As information from the spoken target word unfolded, fixations to all three types of competitors diverged from fixations to the unrelated distractors. As in Huettig and McQueen (2007, Experiment I), fixations to the phonological competitors diverged around $300 \mathrm{~ms}$ after word onset and earlier than looks to the semantic competitors and the shape competitors. One possibility for this pattern of competitor fixations is that it reflects continuous information flow from the speech signal, via a phonological level of lexical representation, to levels of processing where knowledge about visual and semantic features can be retrieved and used (see Huettig \& 
a)

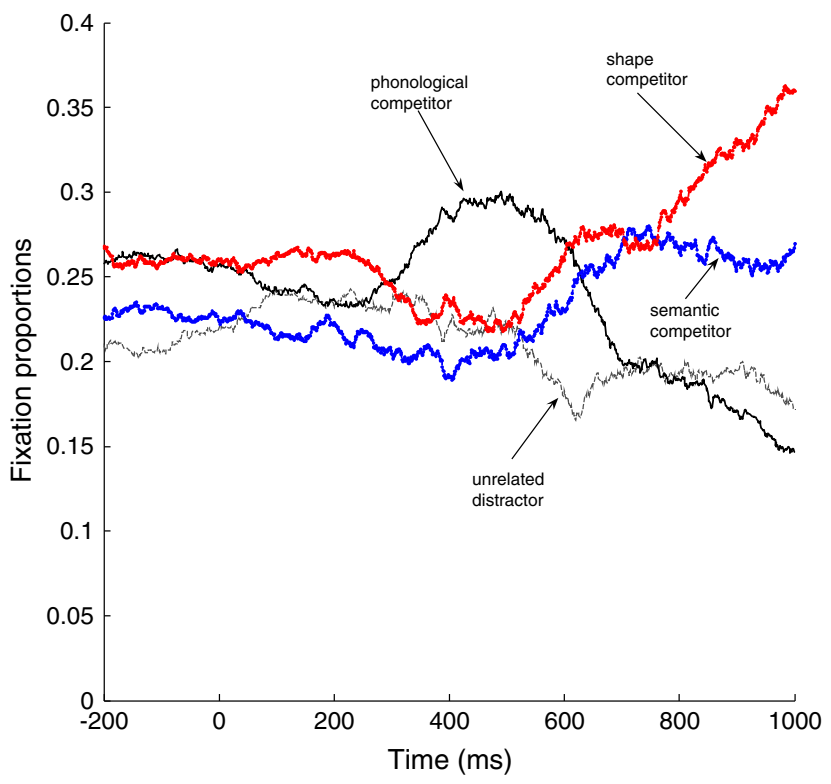

b)

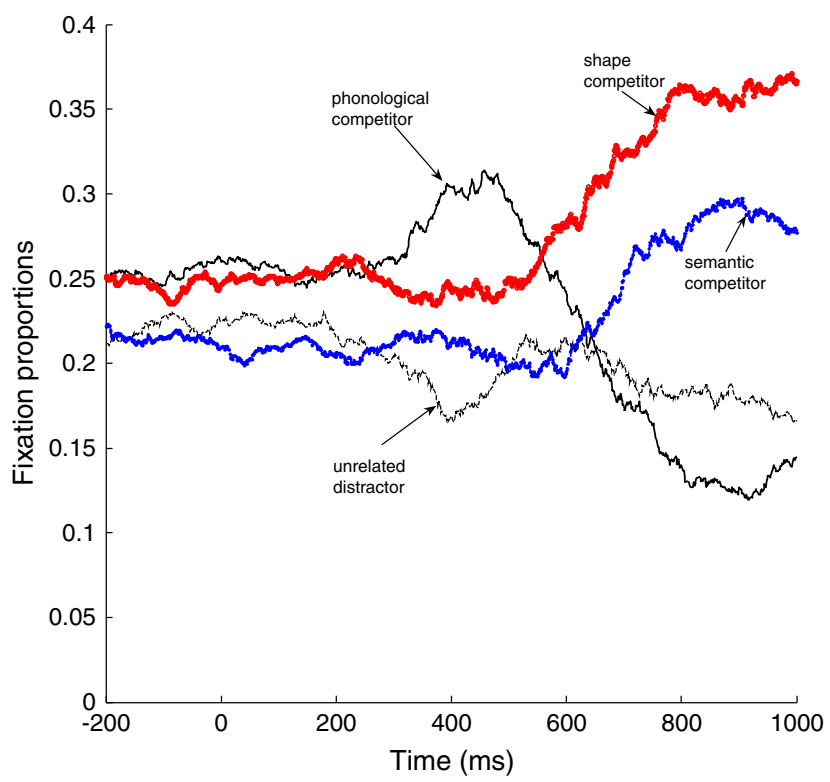

Figure 2. Time-course graph of fixation proportions in Experiment I (panel a: control participants; panel b: adults with dyslexia). Zero represents the onset of the critical target word (e.g., 'beaker').

McQueen, 2007, for further discussion). As acoustic information from the target word (e.g., 'beaker') started to mismatch with the names of the four objects in the display, the likelihood of fixating the phonological competitors decreased and both participant groups shifted their attention to the shape and the semantic competitors (again closely replicating previous studies). 
For the statistical analysis, the gaze data were analysed for separate $200 \mathrm{~ms}$ time bins. For each $200 \mathrm{~ms}$ time window from the acoustic onset of the critical word, we determined the amount of time our participants looked at each type of object (phonological competitor, semantic competitor, shape competitor, or distractor); that is, we calculated the proportion of looks to phonological competitor, semantic competitor, shape competitor, or distractor during that time window. Fixation proportions were transformed logistically, and zeros and ones were replaced by $0.0 \mathrm{I}$ and 0.99 (cf. Macmillan \& Creelman, 199I). The dependent variable is the difference of the transformed competitor and distractor looks as a function of time (cf. Arai, van Gompel, \& Scheepers, 2007). The measure is symmetrical around zero such that equal proportions of looks yield a score of zero, higher proportions on the competitors result in a positive score, and higher proportions on the distractor result in a negative score. This was carried out separately for phonological, semantic, and shape competitors, both by participant $\left(t_{1}\right)$ and by item $\left(t_{2}\right)$. As a baseline, we computed mean ratios from 200 to I ms before word onset. A three-way mixed ANOVA with group (adults with dyslexia or control participants) as between subject factor and bin (baseline, and the subsequent five $200 \mathrm{~ms}$ bins) and competitor type (phonological, semantic, or shape) as within-subject factors showed no significant main effect of group, $F_{I}(I, 42)=0.17$, $p>. I ; F_{2}(I, 68)=0.04, p>. I$; no significant competitor by group interaction, $F_{1}(2,84)=1.03, p>. I ; F_{2}(2,136)=0.07, p>. I ;$ no significant bin by group interaction, $F_{1}(5,210)=0.67, p>. I ; F_{2}(5,340)=0.35, p>. I$; and no significant three-way interaction between bin, competitor type, and group, $F_{1}(10,420)=1.67$, $p>.05 ; F_{2}(I 0,680)=0.75, p>. I$. There was no significant main effect of bin, $F_{1}(5,210)=1.82, p>.1 ; F_{2}(5,340)=2.10, p>.05$. As expected (and in line with Huettig \& McQueen, 2007, Experiment I), there was a significant main effect of competitor, $F_{1}(2,84)=14.67, p<.00 \mathrm{I} ; F_{2}(2,136)=4.06, p=.019$; and a significant bin by competitor interaction, $F_{1}(10,420)=19.70, p<.00 I ; F_{2}(10,680)$ $=7.53, p<.00 \mathrm{I}$.

\section{Discussion}

Experiment I was conducted to assess whether adults with dyslexia show the same patterns of language-mediated eye gaze as reported in earlier eye-tracking studies with participants with no reading impairments. Eye movements of both adults with dyslexia and control participants closely replicated the earlier research. There were no group differences in time course and magnitude of fixations directed to phonological, semantic, and visual-shape competitors. These results suggest that adults with dyslexia use spoken language to direct attention to relevant objects in the visual environment in a similar manner and at a similar time course as adults with no reading difficulties.

\section{EXPERIMENT 2}

\section{Participants}

The same participants as in Experiment I took part. 


\section{Materials and Design}

Participants received 40 spoken instructions (e.g., 'kijk naar de afgebeelde piano'look at the displayed piano, or 'kijk naar het afgebeelde paard'-look at the displayed horse) while viewing similar four object displays as in Experiment I (see Figure 3 for an example and see APPENDIX B for materials). Importantly, the articles were gender marked such that the article ('de' or 'het'-both translating to the in English) agreed in gender only with the target object, and thus, participants could use gender information from the article to predict the upcoming target object. For example, on one trial (Figure 3a), the target object piano was a 'de word' but the three unrelated distractors (pig, paper, and plate) were neuter

a)

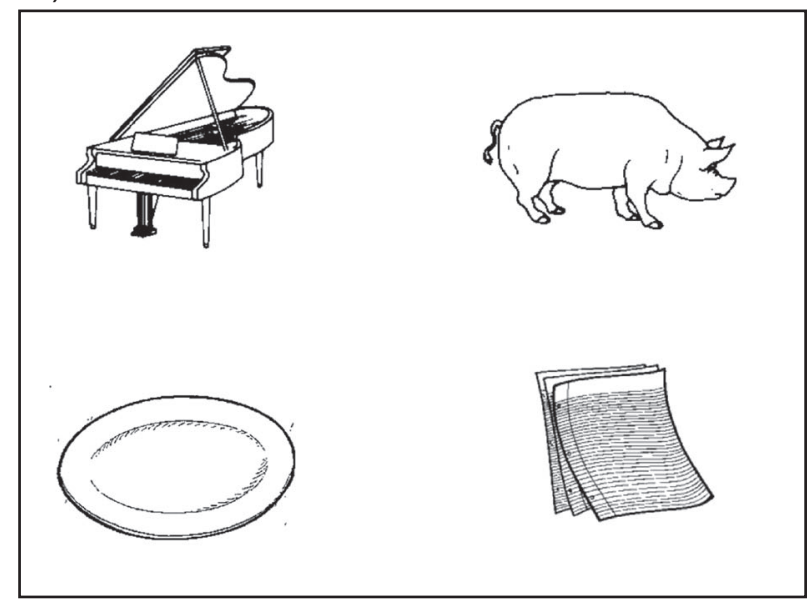

b)

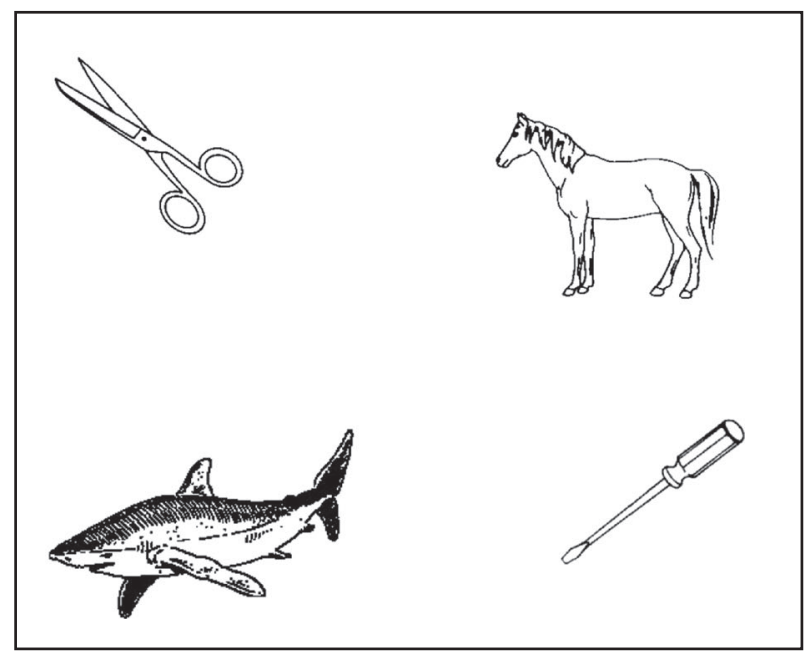

Figure 3. Example displays for one 'de' trial (a, with the target: de piano, and three 'het' unrelated distractors) and a 'het' trial (b, with the target: het paard (horse), and three 'de' unrelated distractors). 
gender ('het') words. Conversely, on some other trials, the target was a neuter gender ('het') word (e.g., 'paard'-horse) but the three unrelated distractors (scissors, shark, and screwdriver) were 'de words'. Twenty of the instructions contained common gender words and 20 other neuter gender words. Common and neuter gender versions of the instructions were randomized. We included the word 'afgebeelde', displayed, between article and noun in the spoken instructions to ensure participants had ample time to anticipate the target object. The average noun onset occurred $2009 \mathrm{~ms}$ after article onset. Target and distractor pictures were line drawings and taken from the Severens, Van Lommel, Ratinckx, and Hartsuiker (2005) set and matched for CELEX word frequency, number of picture names, h-statistic (which compensates for overestimating name agreement when participants assigned many different names infrequently and one single name very frequently), and picture naming time. The 40 spoken instructions were read aloud with a neutral intonation contour by a female native speaker of Dutch in a sound-damped booth. In order to allow both participant groups ample time for prediction, spoken instructions were recorded in a well-articulated (i.e., carefully pronounced relatively slow but fluent) speech style. Digital recordings (sample rate $44.1 \mathrm{kHz}, 16$ bit sampling resolution) were stored on computer.

\section{Procedure}

On each trial, a central fixation dot appeared allowing for drift correction. Then, the visual displays appeared. Two thousand milliseconds after the pictures appeared, the auditory presentation of the spoken instructions was initiated. After the onset of the instruction, the display remained on the screen for a further $5000 \mathrm{~ms}$, followed by a $500 \mathrm{~ms}$ blank screen. Participants were told to listen to the instructions of the speaker (e.g., 'look at the displayed piano'). They were reminded not to take their eyes off the screen if possible.

\section{Results}

Figure 4 shows a time-course graph of the proportions of fixations to the target objects specified in the instruction and the unrelated distractors plotted from

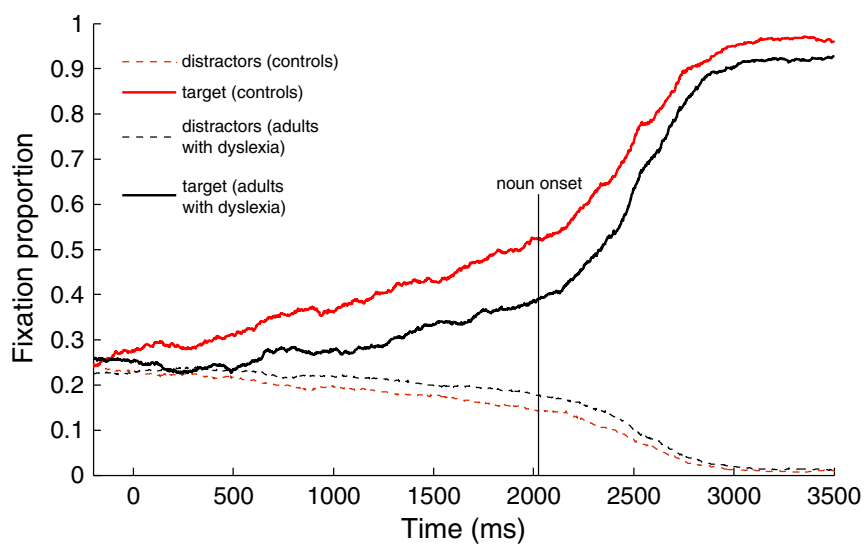

Figure 4. Time-course graph of fixation proportions in Experiment 2. Zero represents the onset of the article. 
the acoustic onset of the spoken article ('de' or 'het'). The dotted lines show the average proportions of looks to the distractors. The proportions reflect the number of trials in which participants were fixating each type of picture on the screen. Time zero represents the acoustic onset of the article.

The graph suggests that both participant groups anticipated the target object (i.e., looks to the target objects diverged from the looks to the unrelated distractors before noun onset). The graph, however, also suggests that the control participants shifted their eye gaze to the target objects substantially earlier than the adults with dyslexia.

The data were log transformed in the same way as in Experiment I. Distractor fixation proportions were averaged. Target-distractor ratios were computed for the baseline time region and the following ten $200 \mathrm{~ms}$ time bins preceding the critical noun onset (see Table 2). The dependent variable is the difference of the transformed target and distractor looks as a function of time. A two-way ANOVA on the fixation ratio data with group (adults with dyslexia or control participants) as between subject factor and bin (baseline, and the subsequent ten $200 \mathrm{~ms}$ bins) as within-subject factor showed a significant main effect of group, $F_{I}(I, 42)=9.12$, $p=.004 ; F_{2}(I, 78)=13.0, p=.001 ;$ a significant main effect of bin, $F_{1}(10,420)$ $=25.95, p<.00 \mathrm{I} ; F_{2}(I 0,780)=3 \mathrm{I} .27, p<.00 \mathrm{I}$; and a significant bin by group interaction, $F_{1}(I 0,420)=2.30 p=.012 ; F_{2}(I 0,780)=2.44, p=.007$.

We then tested whether the mean target/distractor log ratios during the baseline time window were significantly different from the mean target/distractor log ratios during the subsequent time windows. Mean ratios during the baseline region were calculated to adjust for any bias in overt attention to a type of object (target or distractor) before information from the critical article ('de' or 'het') became available.

For the control participants, paired $t$ tests showed that the target/distractor ratios during the baseline time window first differed significantly from the target/distractor ratios by participants and items during the $400-599 \mathrm{~ms}$ time window, $t_{1}(I, 2 I)=-2.49, p=.02 I ; t_{2}(I, 39)=-3.09, p=.004$. This difference remained statistically reliable during the following $200 \mathrm{~ms}$ time bins (e.g., $600-799 \mathrm{~ms}$ time window, $t_{1}(\mathrm{I}, 2 \mathrm{I})=-3.76, p=.00 \mathrm{I} ; t_{2}(\mathrm{I}, 39)=-4.54, p<.00 \mathrm{I}$;

Table 2. Mean target/distractor log ratios (and standard deviations in parentheses) for both groups between article onset and noun onset in Experiment 2

Mean log ratio

\begin{tabular}{lcc} 
Bin $(\mathrm{ms})$ & Adults with dyslexia & Control participants \\
\hline Baseline $(-200$ to $-\mathrm{I})$ & $0.11(0.62)$ & $0.08(0.77)$ \\
0 to 199 & $0.03(0.70)$ & $0.23(0.84)$ \\
200 to 399 & $-0.04(0.77)$ & $0.22(0.70)$ \\
400 to 599 & $0.02(0.61)$ & $0.34(0.65)$ \\
600 to 799 & $0.17(0.52)$ & $0.50(0.60)$ \\
800 to 999 & $0.19(0.52)$ & $0.58(0.57)$ \\
1000 to 1199 & $0.20(0.61)$ & $0.63(0.65)$ \\
1200 to 1399 & $0.30(0.69)$ & $0.79(0.61)$ \\
1400 to 1599 & $0.44(0.60)$ & $0.89(0.60)$ \\
1600 to 1799 & $0.53(0.49)$ & $1.06(0.68)$ \\
1800 to 1999 & $0.65(0.50)$ & $1.21(0.77)$ \\
\hline
\end{tabular}


800-999 ms time window, $\left.t_{1}(I, 2 I)=-3.68, p=.00 I ; t_{2}(I, 39)=-5.23, p<.00 I\right)$ and thereafter.

For the adults with dyslexia, paired $t$ tests revealed no significant difference between the target/distractor ratios during the baseline time window and the target/distractor ratios during the $400-599 \mathrm{~ms}$ time window, $t_{1}(I, 2 I)=I .2 I$, $p>. I ; t_{2}(I, 39)=0.84, p>. I$, and during the subsequent three $200 \mathrm{~ms}$ time windows $\left(t_{1}\right.$ and $\left.t_{2}<\mathrm{I}\right)$. Similarly, there was no statistical difference between baseline and the $1200-1399 \mathrm{~ms}$ time window, $t_{1}(I, 2 I)=-I .29, p>. I ; t_{2}(I, 39)=-I .25$, $p>$.I. For the adults with dyslexia, the target/distractor ratios during the baseline time window first differed significantly from the target/distractor ratios during the $1400-1599 \mathrm{~ms}$ time window, $t_{1}(\mathrm{I}, 2 \mathrm{I})=-2.35, p=.029 ; t_{2}(\mathrm{I}, 39)=-2.72, p=.0 \mathrm{I}$, and thereafter. Thus, we observed an approximate $1000 \mathrm{~ms}$ delay in anticipatory eye movements in the adults with dyslexia.

\section{Correlational analyses}

Multiple linear regression analysis (stepwise) was used to develop a model for predicting participants' fixation proportions to targets from their scores on the word reading (One-Minute-Test) and pseudoword reading (Klepel) tests during an early (0-999 ms from article onset) and a late (1000-1999 ms from article onset) anticipation time window preceding the onset of the spoken target word. Both predictors were not statistically significant during the first time window $(p>.05)$. For the second time window, the model only contained the scores on the One-Minute-Test and was reached in one step with the Klepel scores removed. The model that included One-Minute-Test (i.e., real word reading) scores accounted for $8.1 \%$ of the variance (adjusted $R^{2}=0.081 ; F(I, 42)=4.806 ; p=0.034$ ). Table 3 reports the correlations between the eye movement behaviour and the control tasks over the two windows.

\section{Discussion}

The aim of Experiment 2 was to examine whether adults with dyslexia show similar language-mediated anticipatory eye movements patterns as controls without reading impairment. Adults without reading impairments showed much earlier anticipatory eye movements to target objects than adults with dyslexia. Interestingly, participants' word reading scores explained $8.1 \%$ of the variance consistent with

Table 3. Correlations between control task and eye movement behaviour during an early (0-999 ms) and a late (1000-1999 ms) time window

\begin{tabular}{lcccccr}
\hline Measure & \multicolumn{1}{c}{1} & 2 & 3 & 4 & 5 & 6 \\
\hline I. One-Minute-Test & \multicolumn{1}{c}{ - } & & & & & \\
2. Klepel & $0.734^{* * * * *}$ & - & & & \\
3. Pseudoword spelling & $0.322^{* * *}$ & $0.473^{* * *}$ & - & & \\
4. Verbal competence & 0.131 & 0.067 & 0.237 & - & & \\
5. Early: $0-999 \mathrm{~ms}$ & 0.90 & 0.118 & $0.347^{*}$ & 0.185 & - & - \\
6. Late: $1000-1999 \mathrm{~ms}$ & $0.320^{*}$ & $0.279^{*}$ & 0.155 & 0.142 & - & - \\
\hline
\end{tabular}

${ }^{*} p<.05 ; * * 0.01 ; * * 2 \% p<.001$. 
the notion that (real) word reading skills are related to language-mediated anticipatory eye moments (although the variance explained by word reading scores in the present study is considerably smaller than in previous studies, e.g., the $18 \%$ variance explained in Mani \& Huettig, 20I4).

\section{GENERAL DISCUSSION}

In two eye-tracking experiments, Dutch adults with dyslexia and control participants without reading disorders listened to spoken sentences while viewing visual displays of four objects. The pattern of language-mediated eye movements to phonological, semantic, and shape competitor objects of spoken target words of both adults with dyslexia and control participants in Experiment I was very similar in the time course and magnitude to the patterns reported in earlier research. Experiment I therefore shows that adults with dyslexia use spoken language to direct attention to relevant objects in the visual environment in a very similar manner as adults without reading impairments. In Experiment 2, both participant groups heard instructions such 'Kijk naar de com afgebeelde piano ${ }_{\text {com' (look at }}$ the displayed piano) while viewing the four objects. The Dutch articles ('het' or 'de') were gender marked such that the article agreed in gender only with the target. Participants therefore could use gender information from the article to predict the upcoming target. Both participant groups anticipated the target well in advance of the acoustic onset, but the adults with dyslexia did so much later than the control participants.

Given that these group differences emerge in the relatively easy listening situation tested here, we believe that it is highly likely that anticipation differences will be as large or larger in more challenging listening conditions. Future studies however could usefully explore predictive language processing of adults with dyslexia in reduced speech (cf. Brouwer, Mitterer, \& Huettig, 2012) and noisy listening (cf. McQueen \& Huettig, 20I2) conditions.

The present results are in close accordance with the findings of Mishra et al. (2012) who found that illiterates and low literate (in contrast to high literate) adults did not show anticipatory eye movements to concurrent target objects in predictive Hindi sentence constructions. The results also fit with recent findings that word reading scores predict anticipatory language processing in 8-yearolds (i.e., children at the cusp of acquiring literacy; Mani \& Huettig, 2014).

These data therefore provide further evidence that literacy modulates predictive spoken language processing. High reading proficiency appears to be important even for prediction in basic every day spoken language processing. Is literacy simply a proxy for language experience? According to this explanation, the delay in predictive spoken language processing in adults with dyslexia is not a direct consequence of dyslexia but a secondary consequence of reduced exposure to written stimuli and reading practice and, by extension, less linguistic experience more generally (cf. Perfetti \& Hart, 2002; Perfetti, 2007; Tunmer \& Chapman, 2012; Van Dyke, Johns, \& Kukona, 2014). Or, does reading proficiency fine-tune anticipatory mechanisms in more specific ways? For instance, reading and spoken language comprehension differ in the amount (approx. 250 vs I 50 words $/ \mathrm{min}$ ) of information that is processed per time unit. In order to maintain such, a high reading speed prediction is likely to be helpful. Many 
reading studies have shown that high-predictable words are read faster than low-predictable words (e.g., Ehrlich \& Rayner, I98I; Rayner \& Well, 1996).

Do the group differences observed in the present study simply reflect that adults with dyslexia have slower eye movements more generally? There is little evidence in support of such a notion. Note that almost all studies on oculomotor control and dyslexia have focused on differences in oculomotor control in reading. Rayner (1998) concluded in a review of that literature that in the vast majority of individuals with dyslexia, eye movements reflect a language processing deficit rather than a visual/spatial deficit (see also Bellocchi, Muneaux, Bastien-Toniazzo, \& Ducrot, 2013, for a recent comprehensive discussion on the link between eye movements and visuo-attentional processes). The strongest evidence, however, against the notion that there is a general slowing in language-mediated eye movements in adults with dyslexia is the results of the present Experiment I. There was no hint of a delay in language-mediated eye movements in the dyslexic group in Experiment I (i.e., looks to phonological, semantic, and visual competitors). Moreover, the eye gaze pattern of the adults with dyslexia in Experiment I also closely resembled those of the control participants. This strongly suggests that the general word-object mapping behaviour of adults with dyslexia is as fast and efficient as that of adults with no reading disorders.

A related possibility for the delay in anticipatory eye movements in adults with dyslexia is a general processing speed deficit. General processing speed has been linked to individual differences in many cognitive tasks (e.g., Kail \& Salthouse, 1994; Salthouse, 1996). Processing speed may be related to the speed with which neural signals are conducted along axons. Speed of neural transmission is related to the degree of myelination (Gutiérrez, Boison, Heinemann, \& Stoffel, 1995), and there is evidence that learning increases myelination (cf. Bengtsson et al., 2005). This could potentially provide a mechanism by which learning to read enhances processing speed. A growing body of evidence indeed suggests that children with dyslexia have speed of processing impairments (Breznitz \& Meyler, 2003; Catts, Gillispie, Leonard, Kail, \& Miller, 2002; Fawcett, Nicolson, \& Dean, 1996; Nicolson \& Fawcett, 1994; Sobotka \& May, 1977; Stringer \& Stanovich, 2000). Bonifacci and Snowling (2008), however, have presented evidence that speed of information processing is normal in dyslexia. Again, the data of Experiment I make it very unlikely that a general processing speed deficit caused the delay in the present visual world task. Similar to the arguments earlier against a general slowing of oculomotor control, a processing speed deficiency account fails to explain why there were no differences in the speed of attentional shifts to the various competitors in Experiment I.

A further account for the anticipation differences in the present study relies on the assumption that frequent reading practice strengthens associative links between words or increases the forward transitional probabilities between words (McDonald \& Shilcock, 2003; but see Frisson, Rayner, \& Pickering, 2005). Forward transitional probabilities refer to the likelihood that a particular word will follow given another word. High literates may be able to exploit these dependencies. Note, however, that in the present study, participants heard Dutch articles ('het' or 'de') to predict words (and its visual referents) that agreed in gender with the articles. Given the vast number of words that 
agree in gender with 'het' or 'de', it seems unlikely that simple associations or transitional probabilities underlie the delay in anticipatory eye movements in the adults with dyslexia in the present study. Of course, this does not rule out that associations and transitional probabilities are related to predictive language processing in other situations.

Finally, one may ask whether the present results are informative with regard to the debate whether literacy leads to changes of pre-existing phonological representations (Harm \& Seidenberg, 1999, 2004; Muneaux \& Ziegler, 2004; Pattamadilok, Knierim, Duncan, \& Devlin, 2010; Perre, Pattamadilok, Montant, \& Ziegler, 2009; Smith et al., 20 I 4; Taft \& Hambly, 1985) or to online activation of orthographic representations during speech processing (Grainger, Diependaele, Spinelli, Ferrand, \& Farioli, 2003; Grainger \& Ferrand, 1996; Ziegler \& Ferrand, 1998).

In line with the phonological restructuring account, orthographic input may lead to more fine-grained phonological representations and, by extension, to more efficient phonological processing supporting anticipation of upcoming input. What may speak against this possibility is that in our present study, anticipatory eye gaze to targets was predicted by word reading skills but not participants' pseudoword reading skills. Pseudoword reading provides a more appropriate measure of decoding skills (and more fine-grained phonological representations; cf. Ziegler \& Goswami, 2005) than word reading. This could be interpreted as providing little support for the notion that differences in the decoding skills of our participants are causally related to the time-course differences in anticipatory spoken language processing observed here. On the other hand, word reading skills may be related to the sharpness of lexical representations (in line with the phonological restructuring account). Based on their finding that word reading scores predict anticipatory language processing in 8-year-olds, Mani and Huettig (20l4), for instance, favoured an account in which the process of efficient learning of orthographic representations during reading acquisition leads to a sharpening of pre-existing lexical representations. These sharpened representations, they suggest, support the anticipation of upcoming spoken words. Sharper lexical representations may be retrieved more rapidly and thus help the listener to anticipate how the speaker may continue his or her utterance. The variance explained by word reading scores in the present study was much smaller ( $8.1 \%$ vs $18 \%)$ than in Mani and Huettig (2014). Moreover, word reading scores in the present study were only a robust predictor of anticipation in the later (pre-target noun) time window (which possibly suggests that it takes some time for an influence of word reading skill on language-mediated anticipation to emerge). There are, however, important differences between the present study and the Mani and Huettig (2014) study that differed in type of participant population, anticipation cue, and language used.

The present results may also be compatible with online activation of orthographic representations during speech processing. Rapid online retrieval of orthographic information may lead to fast(er) retrieval of lexical representations and thus also support efficient processing and anticipation of upcoming spoken language input. Indeed, the phonological restructuring and the online activation account are not mutually exclusive and may well both play a role. Further empirical and computational work is required to test whether sharpened lexical representations or online activation of orthographic representations during speech processing aids prediction and to investigate the exact mechanisms by which literacy affects anticipatory spoken language processing. 
To conclude, the current study observed that adults with dyslexia could use gender information from Dutch articles in simple Dutch spoken instructions to predict which target object a speaker would refer to next. Crucially, however, these language-mediated anticipatory eye movements in adults with dyslexia occurred much later than in a control group of adults with no reading impairments. Participants' anticipation of the targets correlated positively with their word reading skills. These findings provide further evidence that literacy (and more specifically word reading skill) is related to the prediction of upcoming spoken language input.

\section{APPENDIX A: MATERIALS OF EXPERIMENT I}

\begin{tabular}{|c|c|c|c|c|}
\hline Spoken word & Shape competitor & Semantic competitor & $\begin{array}{l}\text { Phonological } \\
\text { competitor }\end{array}$ & $\begin{array}{l}\text { Unrelated } \\
\text { distractor }\end{array}$ \\
\hline boon (bean) & sabel (sword) & sla (lettuce) & boog (bow) & cello (cello) \\
\hline hoefijzer & magneet (magnet) & zadel (saddle) & hoed (hat) & filter (filter) \\
\hline peddel (paddle) & fluit (flute) & zeilboot (sailing boat) & perzik (peach) & bril (glasses) \\
\hline ballon (balloon) & zon (sun) & pop (doll) & bad (bath) & deur (door) \\
\hline raket (rocket) & fles (bottle) & vlieger (kite) & ratel (rattle) & Emmer (bucket) \\
\hline arm (arm) & rietje (straw) & nier (kidney) & $\begin{array}{l}\text { artisjok } \\
\text { (artichoke) }\end{array}$ & muts (hat) \\
\hline hart (heart) & voetbal (football) & gebit (teeth) & $\begin{array}{l}\text { hamster } \\
\text { (hamster) }\end{array}$ & $\begin{array}{l}\text { bloemkool } \\
\text { (cauliflower) }\end{array}$ \\
\hline ananas & boei (buoy) & pinda (peanut) & agent (policeman) & spijker (nail) \\
\hline $\begin{array}{l}\text { (PIneapple) } \\
\text { paleis (palace) }\end{array}$ & kennel (kennel) & koning (kins & paling (eel) & slee (sledge) \\
\hline bal (ball) & kers (cherry) & shuttle (shuttlecock) & bank (sofa) & hond (dog) \\
\hline Ielie (lily) & kroon (crown) & cactus (cactus) & lepel (spoon) & mossel (mussel) \\
\hline kerk (church) & igloo (igloo) & graf (grave) & ketting (chain) & pan (pot) \\
\hline $\begin{array}{l}\text { berg } \\
\text { (mountain) }\end{array}$ & servet (napkin) & wolk (cloud) & bel (bell) & kies (tooth) \\
\hline boor (drill) & pijl (arrow) & ladder (ladder) & boom (tree) & neus (nose) \\
\hline bord (plate) & wiel (wheel) & karaf (carafe) & bot (bone) & aap (ape) \\
\hline koffer (suitcase) & schilderij (picture) & tent (tent) & $\begin{array}{l}\text { kompas } \\
\text { (compass) }\end{array}$ & mug (mosquito) \\
\hline tang (pliers) & broek (trousers) & $\begin{array}{l}\text { fietspomp (bicycle } \\
\text { pump) }\end{array}$ & tak (twig) & oor (ear) \\
\hline liniaal (ruler) & kam (comb) & kubus (cube) & libel (dragonfly) & paprika (pepper) \\
\hline das (tie) & veer (feather) & trui (jumper) & dak (roof) & trommel (drum) \\
\hline moer (nut) & donut (donut) & hamer (hammer) & moeder (mother) & laars (boot) \\
\hline dolk (dagger) & $\begin{array}{l}\text { kurkentrekker } \\
\text { (corkscrew) }\end{array}$ & kanon (cannon) & dorp (village) & television (TV) \\
\hline fakkel (torch) & ijsje (ice cream) & bom (bomb) & fabriek (factory) & knoop (button) \\
\hline $\begin{array}{l}\text { schildpad } \\
\text { (turtle) }\end{array}$ & ton (barrel) & haai (shark) & schip (ship) & $\begin{array}{l}\text { penseel } \\
\text { (paintbrush) }\end{array}$ \\
\hline beker (beaker) & klos (bobbin) & vork (fork) & bever (beaver) & $\begin{array}{l}\text { paraplu } \\
\text { (umbrella) }\end{array}$ \\
\hline hek (fence) & rail (railway line) & sleutel (key) & helm (helmet) & tas (bag) \\
\hline ketel (kettle) & slot (lock) & vijzel (jack) & kegel (cone) & $\operatorname{vos}(f \circ x)$ \\
\hline riem (belt) & slang (snake) & sandaal (sandal) & riet (reed) & asbak (ashtray) \\
\hline kogel (bullet) & ui (onion) & speer (spear) & konijn (rabbit) & vest (waistcoat) \\
\hline
\end{tabular}




\section{APPENDIX B: MATERIALS OF EXPERIMENT 2}

\begin{tabular}{|c|c|c|c|}
\hline Target & Unrelated distractor I & Unrelated distractor2 & Unrelated distractor3 \\
\hline de krokodil & anker & gewei & bed \\
\hline de appel & bot & boek & kleed \\
\hline de fiets & koekje & ei & oor \\
\hline de auto & hek & vuur & meisje \\
\hline de vork & graf & geweer & hart \\
\hline de fontein & lieveheersbeestje & blad & hoefijzer \\
\hline de hoed & glas & haar & slot \\
\hline de sok & net & stoplicht & zeepaardje \\
\hline de koelkast & konijn & cadeau & zwembad \\
\hline de piano & bord & varken & papier \\
\hline de trompet & zwaard & tennisracket & horloge \\
\hline de tandenborstel & raam & vuilnis & pak \\
\hline de sneeuwpap & nijlpaard & standbeeld & spinnewiel \\
\hline de ster & spinnenweb & stinkdier & skelet \\
\hline de schoen & skateboard & schaap & stuur \\
\hline de weegschaal & zoutvaatje & zadel & wiel \\
\hline de pyramide & touw & dak & scheermesje \\
\hline de politieman & vlot & stekelvarken & ijsje \\
\hline de neus & kussen & schilderij & potlood \\
\hline de spijker & pakket (je) & orgel & nest \\
\hline het luipaard & barbeque & appel & pijl \\
\hline het spaarvarken & mier & bijl & rugtas \\
\hline het masker & vleermuis & bal & mand \\
\hline het been & asbak & beer & tak \\
\hline het kruis & ring & fles & brug \\
\hline het blik & bezem & stoel & olifant \\
\hline het hert & cel & kaas & kikker \\
\hline het brood & kano & kist & geit \\
\hline het aquarium & kameel & schoorsteen & handschoen \\
\hline het schip & ketting & kaars & zebra \\
\hline het balkon & kerk & rits & windmolen \\
\hline het vliegtuig & gieter & kruiwagen & paraplu \\
\hline het fluitje & vleugel & vaas & boom \\
\hline het oog & vulkaan & TV & slak \\
\hline het kasteel & glijbaan & rok & ski \\
\hline het paard & schaar & schroevendraaier & haai \\
\hline het kanon & roos & pot & bever \\
\hline het springtouw & radio & koningin & puzzel \\
\hline het mes & zeilboot & pinguin & lucifer \\
\hline het strijkijzer & muis & spiegel & mok \\
\hline
\end{tabular}

\section{REFERENCES}

Aglioti, S. M., Cesari, P., Romani, M., \& Urgesi, C. (2008). Action anticipation and motor resonance in elite basketball players. Nature Neuroscience, I I(9), I I09-I I I6.

Altmann, G. T. M., \& Kamide, Y. ( 1999$)$. Incremental interpretation at verbs: Restricting the domain of subsequent reference. Cognition, 73, 247-264.

Altmann, G., \& Mirković, J. (2009). Incrementality and prediction in human sentence processing. Cognitive Science, 33(4), 583-609.

Arai, M., Van Gompel, R. P., \& Scheepers, C. (2007). Priming ditransitive structures in comprehension. Cognitive Psychology, 54(3), 218-250. 
Baayen, R. H., Davidson, D. J., \& Bates, D. M. (2008). Mixed-effects modeling with crossed random effects for subjects and items. Journal of Memory and Language, 59, 390-4I2.

Baddeley, A. D., Ellis, N. C., Miles, T. R., \& Lewis, V. J. (1982). Developmental and acquired dyslexia: A comparison. Cognition, II, I85-199.

Bellocchi, S., Muneaux, M., Bastien-Toniazzo, M., \& Ducrot, S. (20I3). I can read it in your eyes: What eye movements tell us about visuo-attentional processes in developmental dyslexia. Research in Developmental Disabilities, 34(I), 452-460.

Bengtsson, S. L., Nagy, Z., Forsman, L., Forssberg, H., Skare, S., \& Ullén, F. (2005). Extensive piano practising has regionally specific effects on white matter development. Nature Neuroscience, 8(9), II48-II50.

Blom, E., Polišenská, D., \& Weerman, F. (2008). Articles, adjectives and age of onset: The acquisition of Dutch grammatical gender. Second Language Research, 24(3), 297-33I.

Blomert, L., \& Mitterer, H. (2004). The fragile nature of the speech-perception deficit in dyslexia: Natural vs. synthetic speech. Brain and Language, 89(I), 2I-26.

Borovsky, A., Elman, J., \& Fernald, A. (20I2). Knowing a lot for one's age: Vocabulary and not age is associated with incremental sentence interpretation in children and adults. Journal of Experimental Child Psychology, I/2, 4I7-436.

Brady, S., Shankweiler, D., \& Mann, V. (1983). Speech perception and memory coding in relation to reading ability. Journal of Experimental Child Psychology, 35, 345-367.

Breznitz, Z., \& Meyler, A. (2003). Speed of lower-level auditory and visual processing as a basic factor in dyslexia: Electrophysiological evidence. Brain and Language, 85, 166-184.

Brouwer, S., Mitterer, H., \& Huettig, F. (2012). Speech reductions change the dynamics of competition during spoken word recognition. Language and Cognitive Processes, 27(4), 539-57I.

Brus, B. T., \& Voeten, M. J. M. (1973). Een-Minuut-Test. Nijmegen (The Netherlands): Berkhout.

Bonifacci, P., \& Snowling, M. J. (2008). Speed of processing and reading disability: A cross-linguistic investigation of dyslexia and borderline intellectual functioning. Cognition, 107, 999-1017.

Catts, H., Gillispie, M., Leonard, L., Kail, R., \& Miller, C. (2002). The role of speed of processing, rapid naming, and phonological awareness in reading achievement. Journal of Learning Disabilities, 35, 509-524.

Clark, A. (2013). Whatever next? Predictive brains, situated agents, and the future of cognitive science. Behavioural and Brain Sciences, 36(3), I-73.

Cooper, R. M. (1974). The control of eye fixation by the meaning of spoken language: A new methodology for the real-time investigation of speech perception, memory, and language processing. Cognitive Psychology, 6(I), 84-107.

Cornelissen, P., Munro, N., Fowler, S., \& Stein, J. (1993). The stability of binocular fixation during reading in adults and children. Developmental Medicine and Child Neurology, 35, 777-787.

Dell, G. S., \& Chang, F. (2014). The P-chain: Relating sentence production and its disorders to comprehension and acquisition. Philosophical Transactions of the Royal Society B, 369, 20120394.

DiBenedetto, B., Richardson, E., \& Kochnower, J. (1983). Vowel generalization in normal and learning disabled readers. Journal of Educational Psychology, 75, 576-582.

Dijkstra, T., Roelofs, A., \& Fieuws, S. (1995). Orthographic effects on phoneme monitoring. Canadian Journal of Experimental Psychology, 49, 264-27I.

DeLong, K. A., Urbach, T. P., \& Kutas, M. (2005). Probabilistic word pre-activation during language comprehension inferred from electrical brain activity. Nature Neuroscience, 8(8), I I I7-I I I .

Dixon, P. (2008). Models of accuracy in repeated-measures design. Journal of Memory and Language, $59,447-456$.

Ehrlich, S., \& Rayner, K. (I98I). Contextual effects on word perception and eye movements during reading. Journal of Verbal Learning and Verbal Behavior, 20, 64I-655.

Fawcett, A. J., Nicolson, R. I., \& Dean, P. (1996). Impaired performance of children with dyslexia on a range of cerebellar tasks. Annals of Dyslexia, 46, 259-283.

Federmeier, K. D., \& Kutas, M. (1999). A rose by any other name: Long-term memory structure and sentence processing. Journal of Memory and Language, 4I, 469-495. 
Frisson, S., Rayner, K., \& Pickering, M. (2005). Effects of contextual predictability and transitional probability on eye movements during reading. Journal of Experimental Psychology: Learning, Memory, and Cognition, 3 I (5), 862-877.

Frost, R., \& Katz, L. (1989). Orthographic depth and the interaction of visual and auditory processing in word recognition. Memory \& Cognition, 17, 302-310.

Geelhoed, J., \& Reitsma, P. (1999). PI-dictee. Lisse, the Netherlands: Swets \& Zeitlinger.

Godfrey, J. J., Sydral-Lasky, A. K., Millay, K. K., \& Knox, C. M. (I98I). Performance of dyslectic children on speech perception tests. Journal of Experimental Child Psychology, 32, 40 I-424.

Goswami, U. (2003). Why theories about developmental dyslexia require developmental designs. Trends in Cognitive Sciences, 7, 534-540.

Grainger, J., \& Ferrand, L. (1996). Masked orthographic and phonological priming in visual word recognition and naming: Cross-task comparisons. Journal of Memory and Language, 35(5), 623-647.

Grainger, J., Diependaele, K., Spinelli, E., Ferrand, L., \& Farioli, F. (2003). Masked repetition and phonological priming within and across modalities. Journal of Experimental Psychology: Learning, Memory, and Cognition, 29(6), 1256.

Gutiérrez, R., Boison, D., Heinemann, U., \& Stoffel, W. (1995). Decompaction of CNS myelin leads to a reduction of the conduction velocity of action potentials in optic nerve. Neuroscience Letters, 195(2), 93-96.

Hallé, P., Chéreau, C., \& Segui, J. (2000). Where is the /b/ in "absurde" [apsyrd]? It is in French listeners' minds. Journal of Memory and Language, 43, 618-639.

Hari, R., \& Renvall, H. (200I). Impaired processing of rapid stimulus sequences in dyslexia. Trends in Cognitive Science, 5(I2), 525-532.

Harm, M. W., \& Seidenberg, M. S. ( 1999$)$. Phonology, reading acquisition, and dyslexia: Insights from connectionist models. Psychological Review, 106(3), 491.

Harm, M. W., \& Seidenberg, M. S. (2004). Computing the meanings of words in reading: Cooperative division of labor between visual and phonological processes. Psychological Review, I I I (3), 662.

Holligan, C., \& Johnston, R. (1988). The use of phonological information by good and poor readers in memory and reading tasks. Memory and Cognition, 6, 522-532.

Huettig, F. (in press). Four central questions about prediction in language processing. Brain Research. http://dx.doi.org/10.1016/j.brainres.2015.02.014

Huettig, F., \& Altmann, G. T. M. (2005). Word meaning and the control of eye fixation: Semantic competitor effects and the visual world paradigm. Cognition, 96(I), B23-B32.

Huettig, F., \& McQueen, J. M. (2007). The tug of war between phonological, semantic and shape information in language-mediated visual search. Journal of Memory and Language, 57(4), 460-482.

Huettig, F., \& Mishra, R. K. (2014). How literacy acquisition affects the illiterate mind-A critical examination of theories and evidence. Language and Linguistics Compass, 8(I0), 40I-427.

Huettig, F., Mishra, R. K., \& Olivers, C. N. (2012). Mechanisms and representations of languagemediated visual attention. Frontiers in Psychology, 2, 394.

Huettig, F., Rommers, J., \& Meyer, A. S. (20II). Using the visual world paradigm to study language processing: A review and critical evaluation. Acta Psychologica, 137, I5I-I7I.

Huettig, F., Singh, N., \& Mishra, R. K. (20I I). Language-mediated visual orienting behavior in low and high literates. Frontiers in Psychology, 2, 285.

Hurford, D. P., \& Sanders, R. E. (1990). Assessment and remediation of a phonemic discrimination deficit in reading disabled second- and fourth-graders. Journal of Experimental Child Psychology, 50, 396-4I5.

James, W. (1890). The principles of psychology I. New York: Dover Publications.

Kamhi, A. G., \& Catts, H. W. (1986). Toward an understanding of developmental language and reading disorders. Journal of Speech and Hearing Disorders, 5I, 337-347.

Kamide, Y., Scheepers, C., \& Altmann, G. T. M. (2003). Integration of syntactic and semantic information in predictive processing: Cross-linguistic evidence from German and English. Journal of Psycholinguistic Research, 32, 37-55.

Kail, R., \& Salthouse, T. A. (1994). Processing speed as a mental capacity. ActPsychologica, 86, 199-225. 
Knoeferle, P., Crocker, M. W., Scheepers, C., \& Pickering, M. J. (2005). The influence of immediate visual context on incremental thematic role-assignment: Evidence from eye-movements in depicted events. Cognition, 95(I), 95-127.

Kochnower, J., Richardson, E., \& DiBenedetto, B. (1983). A comparison of the phonic decoding ability of normal and learning disabled children. Journal of Learning Disabilities, 16, 348-35I.

Kosmidis, M. H., Tsapkini, K., Folia, V., Vlahou, C. H., \& Kiosseoglou, G. (2004). Semantic and phonological processing in illiteracy. Journal of the International Neuropsychological Society, 10(6), I I8-827.

Macmillan, N. A., \& Creelman, C. D. (199I). Detection theory: A user's guide. Cambridge: Cambridge University Press.

Mani, N., \& Huettig, F. (2012). Prediction during language processing is a piece of cake-but only for skilled producers. Journal of Experimental Psychology: Human Perception and Performance, 38(4), 843-847.

Mani, N., \& Huettig, F. (20I4). Word reading skill predicts anticipation of upcoming spoken language input: A study of children developing profliciency in reading. Journal of Experimental Child Psychology, 126, 264-279.

McDonald, S. A., \& Shilcock, R. C. (2003). Low-level predictive inference in reading: The influence of transitional probabilities on eye movements. Vision Research, 43, I735-175I.

McQueen, J. M., \& Huettig, F. (20I2). Changing only the probability that spoken words will be distorted changes how they are recognized. The Journal of the Acoustical Society of America, I3I(I), 509-5I7.

McQueen, J. M., \& Huettig, F. (20I4). Interference of spoken word recognition through phonological priming from visual objects and printed words. Attention, Perception, \& Psychophysics, 76, 190-200.

Mishra, R. K., Singh, N., Pandey, A., \& Huettig, F. (20I2). Spoken language-mediated anticipatory eye movements are modulated by reading ability: Evidence from Indian low and high literates. Journal of Eye Movement Research, 5(I):3, I-10.

Mody, M., Studdert-Kennedy, M., \& Brady, S. (1997). Speech perception deficits in poor readers: Auditory processing or phonological coding? Journal of Experimental Child Psychology, 64, 199-23I.

Muneaux, M., \& Ziegler, J. (2004). Locus of orthographic effects in spoken word recognition: Novel insights from the neighbour generation task. Language and Cognitive Processes, 19(5), 64I-660.

Nation, K., Marshall, C., \& Altmann, G. T. M. (2003). Investigating individual differences in children's real-time sentence comprehension using language mediated eye movements. Journal of Experimental Child Psychology, 86, 314-329.

Nicolson, R., Fawcett, A. J., \& Dean, P. (200I). Dyslexia, development and the cerebellum. Trends in Neuroscience, 24, 5I5-516.

Nicolson, R. I., \& , Fawcett, A. J. (1994). Reaction times and dyslexia. Quarterly Journal of Experimental Psychology, 47A, 29-48.

Olson, R., Kliegl, R., Davidson, B., \& Foltz, G. (1985). Individual and developmental differences in reading disability. In G. E. MacKinnon, \& T. Waller (Eds.), Reading research: Advances in theory and practice (Vol. 4, pp. I-64). San Diego, CA: Academic Press.

Olson, R., Wise, B., Conners, F., \& Rack, J. (1990). Organization, heritability, and remediation of component word recognition and language skills in disabled readers. In T. H. Carr, \& B. A. Levy (Eds.), Reading and its development: Component skills approaches (pp. 26I-322). San Diego, CA: Academic.

Pattamadilok, C., Knierim, I. N., Duncan, K. J. K., \& Devlin, J. T. (2010). How does learning to read affect speech perception? The Journal of Neuroscience, 30(25), 8435-8444.

Pattamadilok, C., Perre, L., Dufau, S., \& Ziegler, J. C. (2009). On-line orthographic influences on spoken language in a semantic task. Journal of Cognitive Neuroscience, 2I, 169-179.

Perfetti, C. (2007). Reading ability: Lexical quality to comprehension. Scientific Studies of Reading, I / (4), 357-383.

Perfetti, C. A., \& Hart, L. (2002). The lexical quality hypothesis. In L. Verhoeven, C. Elbro, \& P. Reitsma (Eds.), Precursors of functional literacy (Pp. 189-2/3). Amsterdam/Philadelphia: John Benjamins.

Perre, L., Pattamadilok, C., Montant, M., \& Ziegler, J. C. (2009). Orthographic effects in spoken language: On-line activation or phonological restructuring? Brain Research, I275, 73-80. 
Petersson, K. M., Reis, A., Askelöf, S., Castro-Caldas, A., \& Ingvar, M. (2000). Language processing modulated by literacy: A network analysis of verbal repetition in literate and illiterate subjects. Journal of Cognitive Neuroscience, 12(3), 364-382.

Pezzulo, G., Falcone, R., \& Hoffmann, J. (2007). Anticipation and anticipatory behavior. Cognitive Processing, 8(2), 67-70.

Pickering, M. J., \& Garrod, S. (2013). Forward models and their implications for production, comprehension, and dialogue. Behavioral and Brain Sciences, 36(4), 377-392.

Rayner, K. (1998). Eye movements in reading and information processing: 20 years of research. Psychological Bulletin, 124(3), 372.

Rayner, K., \& Well, A. D. (1996). Effects of contextual constraint on eye movements in reading: A further examination. Psychonomic Bulletin \& Review, 3, 504-509.

Reed, M. (1989). Speech perception and the discrimination of brief auditory cues in reading disabled children. Journal of Experimental Child Psychology, 48, 270-292.

Reis, A., \& Castro-Caldas, A. (1997). Illiteracy: A bias for cognitive development. Journal of the International Neuropsychological Society, 3, 444-450.

Reis, A., Guerreiro, M., \& Petersson, K. M. (2003). A sociodemographic and neuropsychological characterization of an illiterate population. Applied Neuropsychology, 10, |91-204.

Roodenrys, S., \& Stokes, J. (200I). Serial recall and nonword repetition in reading disabled children. Reading \& Writing, 14, 379-394.

Salthouse, T. A. (1996). The processing-speed theory of adult age differences in cognition. Psychological Review, 103, 403-428.

Seidenberg, M. S., \& McClelland, J. L. (1989). A distributed, developmental model of word recognition and naming. Psychological Review, 96, 523-568.

Serniclaes, W., Ventura, P., Morais, J., \& Kolinsky, R. (2005). Categorical perception of speech in illiterate adults. Cognition, 98, B35-B44.

Severens, E., Van Lommel, S., Ratinckx, E., \& Hartsuiker, R. J. (2005). Timed picture naming norms for 590 pictures in Dutch. Acta Psychologica, 119, 159-187.

Smith, A., Monaghan, P., \& Huettig, F. (2013). An amodal shared resource model of languagemediated visual attention. Frontiers in Psychology, 4, 528.

Smith, A. C., Monaghan, P., \& Huettig, F. (20I4). Literacy effects on language and vision: Emergent effects from an amodal shared resource (ASR) computational model. Cognitive Psychology, 75, 28-54.

Snowling, M. J. (1980). The development of grapheme-phoneme correspondence in normal and dyslexic readers. Journal of Experimental Child Psychology, 29, 294-305.

Snowling, M. J. (I98I). Phonemic deficits in developmental dyslexia. Psychological Research, 43, 219-234.

Snowling, M. J., Goulandris, N., Bowlby, M., \& Howell, P. (1986). Segmentation and speech perception in relation to reading skill: A developmental analysis. Journal of Experimental Child Psychology, 4I, 489-507.

Sobotka, K. R., \& May, J. G. (1977). Visual evoked potentials and reaction time in normal and dyslexic children. Psychophysiology, 14, 18-24.

Stein, J., Talcott, J., \& Walsh, V. (2000). Controversy about the visual magnocellular deficit in developmental dyslexics. Trends in Cognitive Sciences, 4(6), 209-2I0.

Stoodley, C. J., \& Stein, J. F. (2006). A processing speed deficit in dyslexic adults? Evidence from a peg-moving task. Neuroscience Letters, 399, 264-267.

Stringer, R., \& Stanovich, K. E. (2000). The connection between reaction time and variation in reading ability: Unravelling covariance relationships with cognitive ability and phonological sensitivity. Scientific Studies of Reading, 4, 4I-53.

Taft, M., \& Hambly, G. (1985). The influence of orthography on phonological representations in the lexicon. Journal of Memory and Language, 24(3), 320-335.

Tallal, P. (1980). Auditory temporal perception, phonics, and reading disabilities in children. Brain and Language, 9, 182-198.

Tanenhaus, M. K., Spivey-Knowlton, M. J., Eberhard, K. M., \& Sedivy, J. C. (1995). Integration of visual and linguistic information in spoken language comprehension. Science, 268(5217), 1632-1634. 
Tunmer, W. E., \& Chapman, J. W. (20I2). The simple view of reading redux: Vocabulary knowledge and independent components hypothesis. Journal of Learning Disabilities, 45(5), 453-466.

Van Berkum, J. J. A., Brown, C. M., Zwitserlood, P., Kooijman, V., \& Hagoort, P. (2005). Anticipating upcoming words in discourse: Evidence from ERPs and reading times. Journal of Experimental Psychology: Learning, Memory, and Cognition, 3I(3), 443-467.

Van den Bos, K. P., Spelberg, H. C. L., Scheepstra, A. J. M., \& de Vries, J. R. (1994). De KLEPEL. Een test voor de leesvaardigheid van pseudo-woorden. Nijmegen: Berkhout Testmateriaal.

Van Dyke, J. A., Johns, C. L., \& Kukona, A. (20I4). Low working memory capacity is only spuriously related to poor comprehension. Cognition, I3I, 373-403.

Weber, A., Grice, M., \& Crocker, M. (2006). The role of prosody in the interpretation of structural ambiguities: A study of anticipatory eye movements. Cognition, 99(2), B63-B72.

Wechsler, D. (2000). Wechsler Adult Intelligence Scale WAIS-III-NL. Nederlandstalige bewerking. In Uterwijk, J. M. (Ed.), Lisse (the Netherlands): Swets and Zeitlinger. Herziene technische handleiding 2005. Amsterdam: Harcourt Test Publishers.

Wicha, N. Y. Y., Moreno, E., \& Kutas, M. (2004). Anticipating words and their gender: An eventrelated brain potential study of semantic integration, gender expectancy, and gender agreement in Spanish sentence reading. Journal of Cognitive Neuroscience, I6(7), 1272-1288.

Wolff, P. H. (2002). Timing precision and rhythm in developmental dyslexia. Reading andWriting: An Interdisciplinary Journal, 15, 179-206.

Ziegler, J. C., \& Ferrand, L. (1998). Orthography shapes the perception of speech: The consistency effect in auditory word recognition. Psychonomic Bulletin \& Review, 5, 683-689.

Ziegler, J., \& Goswami, U. (2005). Reading acquisition, developmental dyslexia, and skilled reading across languages: A psycholinguistic grain size theory. Psychological Bulletin, I3I(I), 3-29. 